\title{
REFLEX̃̃O DO AUTOCUIDADO ENTRE OS PROFISSIONAIS DE ENFERMAGEM
}

\author{
Ticiana Assemany Cruz*, Andrezza Martins Costa Carvalho*, Robélia Dorea da Silva** \\ Autora para correspondência: Ticiana Assemany Cruz - tassemany@hotmail.com \\ * Graduada em Enfermagem pela Escola Bahiana de Medicina e Saúde Pública \\ ** Professora da Escola Bahiana de Medicina e Saúde Pública. Mestre em Enfermagem pelo Programa de Pós-Graduação \\ em Enfermagem pela Universidade Federal do Rio de Janeiro
}

\begin{abstract}
Resumo
O autocuidado é um conjunto de ações desenvolvidas para regular as dimensões que afetam o próprio desenvolvimento, esse conceito faz parte da Teoria Geral, escrito em 1991 pela enfermeira Dorothea Orem. O ser humano quando está aparentemente bem e saudável, não se dá a devida importância, só sente a necessidade de rever o estilo de vida, quando algum elemento de suas necessidades humanas básicas é afetado. O objetivo desse trabalho é analisar a prática do autocuidado dos enfermeiros para a efetividade na assistência com o outro. Trata-se de um estudo em caráter de revisão integrativa de literatura, pelo levantamento de 23 estudos publicados entre 2003 a 2014, em revistas indexadas nas bases de dados nacionais. Os resultados apontam que o cuidado - para atingir suas dimensões enfermeiro e paciente - precisa ser bidirecional, compreendendo que o déficit de autocuidado profissional torna mais suscetível a falhas no cuidado e exposição à contaminação. Esse estudo serve como fonte de incentivo para novas pesquisas relacionadas à temática com profissionais de saúde. O cuidado é o atributo fundamental para a enfermagem, mas para exercer em sua plenitude é essencial fazer uso das técnicas corretas, ter um processo de trabalho organizado e prestar seu serviço em um ambiente que proponha qualidade de vida no trabalho, sendo assim conclui-se que são atributos da academia, formar profissionais atuantes no autocuidado, e a organização, que presta serviço ao outro, promover planos de gestão e ergonomia para cuidar de quem cuida, pois somente dessa forma, o cuidador e o paciente sairão fortalecidos dessa relação com uma assistência efetiva.
\end{abstract}

Palavras-chave: Enfermagem; Autocuidado; Qualidade de vida; Saúde do trabalhador. 


\title{
REFLECTION ON THE SELF CARE OF NURSING PROFESSIONALS
}

\begin{abstract}
Self-care is a set of actions designed to adjust the dimensions that affect the development itself . Being so, this concept is part of the general theory written by the nurse Dorothea Orem. The human being when is apparently well and healthy might not pay proper attention to their habits. Usually, one feels the need to change possibly hazardous lifestyle habits when some element of their basic human needs is affected. The aim of this paper is to analyze the practice of self-care among nurses for effectiveness in assisting other people. This is a integrative literature review, comprised by23 studies published between 2003 and 2014 in journals indexed in national databases. The results indicate that self-care must be practiced by the nurses too. Thus the deficit of professional self-care might leave the nurses more susceptible to failures in care for others and more likely to be exposed to contamination. This study serves as a source of incentive for new researches related to the issue among health professionals. Caution is a key attribute for nursing, and hence it demands the use of the correct techniques, organized labor and in an environment that ensues life quality. It has thus been concluded that it is a highrer education dutty to form and train professionals aware of self-care so they can better take care of their patients. Additionally, the organizations must provide health care services to others must be willing to promote ergonomics and health care plans to care for those who work there, because only then effective assistance can be delivered to the patients.
\end{abstract}

Keywords: Nursing; Self-Care; Quality of life; Occupational health.

\section{INTRODUÇÃO}

A teoria busca relacionar fatos, formando uma base científica com estruturas rigorosas e ideias criativas em busca de solução, com visão sistêmica dos fenômenos, abandonando dessa forma o modo empírico de atuação da enfermagem. ${ }^{(1)}$

As teorias da enfermagem, em sua grande maioria, surgiram na década de 50 nos Estados Unidos, no intuito de melhorar a qualidade da assistência com a aplicação de uma ação autônoma, pois até então a profissão era vista como não científica e suas ações baseadas na intuição. ${ }^{(1)}$

O autocuidado faz parte da Teoria Geral da Enfermagem, escrito em 1991 pela enfermeira Dorothea Orem, sendo um conjunto de ações desenvolvidas para regular fatores que afetam o próprio desenvolvimento, atividades em benefício da vida, saúde e bem estar. ${ }^{(2)}$

A saúde não é um bem individual, é um valor coletivo, um bem de todos, devendo cada um gozá-la individualmente, sem prejuízo de outrem e, solidariamente, como todos, sendo assim conceituada pela Organização Mundial da Saúde "como um estado de completo bem-estar físico, mental e social e não somente a ausência de afecções e enfermidade". ${ }^{(1)} \mathrm{Na}$ rotina agitada que as pessoas adotam, para atingir suas metas e padrão de vida, em diversos momentos esquecem de cuidar da sua saúde, que quando acometida por alguma enfermidade, precisa cuidar da doença.

O presente trabalho tem como objetivo analisar a prática do autocuidado dos enfermeiros para a 
efetividade na assistência do cuidado com o outro, tendo como objetivos específicos: levantar os fatores que contribuem para a falta de autocuidado da enfermagem; compreender as relações do autocuidado nas dimensões bio-psico-sócio-espirituais; fomentar uma reflexão a cerca do déficit de autocuidado dos profissionais de enfermagem baseado no modelo de Orem.

A justificativa para a escolha deste tema de estudo está permeada pelo atual conhecimento que o mundo do trabalho está exigindo, cada vez mais, que o trabalhador cuide de si, para melhor cuidar do outro, bem como evitar riscos por acidente de trabalho. Na área de saúde, é muito comum encontrar profissionais que cuidam de outro ser humano e por vezes se esquecem de si mesmos, sendo assim sofrem consequências nocivas em seu labor.

Sabe-se que a saúde é formada por elementos bio-psico-sócio-espitiruais, e este amparo pode oportunizar a promoção da saúde, prevenção de doenças e agravos. A efetividade do cuidado prestado está diretamente vinculada à qualidade de vida no trabalho, e são atributos da organização que presta serviço ao outro, o cuidado com o profissional cuidador. ${ }^{(3)}$

A enfermagem foi classificada pela Health Education Authority como quarta profissão mais estressante no setor público, pelas cobranças, estresse e necessidade de correr contra o relógio para salvar o paciente e ainda atender aos familiares com calma e serenidade. ${ }^{(4)}$

A negligência do cuidado de si é uma reflexão que deve ser realizada pelos profissionais de enfermagem, havendo necessidade de resgatar o cuidado do seu próprio eu, para o exercício pleno da profissão. ${ }^{(3)}$

O interesse pelo tema aumentou e parece coincidir com a preocupação sobre o bem-estar profissional e com as indicações de mudanças conceituais sobre saúde. Desenvolver estudos futuros voltados para a enfermagem, utilizando essas teorias, poderia significar uma contribuição na melhoria das condições de trabalho e aumento na qualidade de vida em todos os âmbitos. ${ }^{(4)}$

\section{METODOLOGIA}

Trata-se de um estudo com coleta de dados realizada a partir de fontes secundárias, por meio de levantamento bibliográfico para a realização de uma revisão integrativa da literatura, tendo como base a pergunta norteadora: A falta de autocuidado das enfermeiras, além de prejudicá-las, interfere na assistência do cuidado ao outro?.

Este método permite a análise de pesquisas relevantes, possibilitando a síntese do conhecimento de um determinado assunto e sumarizar as pesquisas já publicadas para obter conclusões a partir do tema de interesse, em busca de obter um profundo entendimento de um determinado fenômeno, baseando-se em estudos anteriores, sendo necessário apresentar com clareza os resultados dos artigos encontrados, para que o leitor consiga identificar as características reais dos estudos. ${ }^{(5)}$

As etapas, que possibilitaram a operacionalização da revisão, iniciaram pela busca por documentos primários, através da base de dados da Scielo e Biblioteca Virtual da Saúde, como critério de inclusão delimitou-se o período de 2003 a 2014, escritos na língua portuguesa, publicações na íntegra, em caráter de pesquisa de campo, abordagem do tema parcial ou total contemplando a visão dos enfermeiros sob o tema de estudo, com avaliação do WebQualis de $\mathrm{A}_{1}$ a $\mathrm{B}_{2}$ e quatro descritores controlados juntos ao Bireme (DeCS): "enfermagem", "autocuidado", "qualidade de vida" e "saúde do trabalhador".

Os critérios de exclusão foram artigos publicados em língua estrangeira e no período anterior a 2003, que apresenta o tema do autocuidado ao paciente sem reflexões quanto ao papel do profissional cuidador, aqueles que não foram publicados em uma base de dados segura, com avaliação do WebQualis inferior a B2 e trabalhos que diferem de artigo científico.

A leitura do material inicialmente foi exploratória através de resumos dos artigos, seguida de leitura seletiva pelo conteúdo e posteriormente analítica, objetivando a identificação das informações e sin- 
tetizando através de fichamentos para fornecer um relatório parcial sobre o tema em estudo.

No intuito de avaliar a qualidade dos periódicos utilizados para a revisão integrativa, foi consultado o portal WebQualis, alimentado pela Coordenação de Aperfeiçoamento de Pessoa de Nível Superior (Capes), fundado pelo Ministério da Educação;(6) o portal disponibiliza uma lista de periódicos científicos com a classificação dos veículos e a estratificação da qualidade de produção intelectual, em ordem decrescente de $A_{1}$ a $C$, a avaliação ocorre anualmente e é realizada de forma indireta.

Os dados de cada estudo foram extraídos e elaboradas duas tabelas por variáveis para analisar o perfil dos 23 artigos coletados.

\section{RESULTADOS E DISCUSSÃO}

Os resultados emergidos do processo reflexivo e interpretativo, que mediante análise do conteúdo, trazem reflexos no intuito de determinar o tipo de relação no autocuidado como fator principal para cuidado do outro.
O presente artigo compõem sete categorias: Teoria geral da enfermagem; dimensões do profissional enfermeira; autocuidado biológico; autocuidado psicológico; autocuidado social; autocuidado espiritual e atribuições do descuidado.

A apresentação da distribuição dos 23 artigos consultados para a elaboração desta revisão integrativa foi dividida em dois quadros e dois gráficos para melhor interpretação do perfil dos artigos coletados. No quadro 1, estão descritas as revistas de publicação, número de artigos e as respectivas revistas, a base de dados utilizada para encontrar o artigo e estrato organizado pela avaliação do WebQualis, com o estrato mais alto $A_{1}$ e seus subsequentes, já o gráfico 1, representa a porcentagem em relação a quantidade de artigos utilizados e estrato de WebQualis. O gráfico 2, faz referencia a relação do ano de publicação e quantidade de artigos pesquisados e o quadro 2 é composto pelo nome dos autores, tipo de estudo que se tratam os artigos, o ano de publicação na revista, a região que o estudo foi produzido e a região em que o estudo foi publicado.

\begin{tabular}{|l|c|c|c|}
\hline \multicolumn{1}{|c|}{ ReVISTA } & $\begin{array}{c}\text { QUANTIDADE } \\
\text { DE ARTIGOS }\end{array}$ & BASE DE DADOS & EstRATO \\
\hline Latino Am. Enfermagem & 4 & SCIELO & Al \\
\hline Esc Enferm USP & 2 & SCIELO & A2 \\
\hline Acta Paulista Enf & 2 & SCIELO & A2 \\
\hline Brasileira de Enf & 3 & SCIELO & A2 \\
\hline Saúde Pública & 1 & SCIELO & A2 \\
\hline Texto e Contexto de Enf & 1 & SCIELO & A2 \\
\hline Revista Gaúcha & 3 & SCIELO & B1 \\
\hline Esc. Anna Nery & 1 & SCIELO & B1 \\
\hline Estudos de psicologia & 1 & SCIELO & B1 \\
\hline Braz Jor Nurse & 1 & BIREME & B1 \\
\hline Enferm. UERJ & 1 & BIREME & B1 \\
\hline Rev Bras de Saúde Ocupacional & 1 & SCIELO & B2 \\
\hline Einsten & 1 & SCIELO & B2 \\
\hline Enferm UfPE & 1 & REV ELETRONICA & B2 \\
\hline
\end{tabular}

Quadro 1 - Distribuição dos artigos conforme revista de publicação, quantitativo de artigos por base de dados e estrato

Fonte: Elaboração própria com base nos dados bibliográficos. Salvador, 2014. 
De acordo com os resultados no quadro 1, identifica-se que as publicações entre os periódicos foram bem variadas, tendo em vista que o assunto é um tema amplo, e para compreender as dimensões, é necessário recorrer a outras especialidades, como a revista de psicologia, contudo o artigo uti- lizado tem a abordagem dentro do tema proposto: o autocuidado.

A base de dados mais utilizada para a busca dos artigos é a Scielo com $87 \%$ em relação às demais, esse valor é atribuído a maior facilidade em navegar pelo website e rastrear o conteúdo desejado.

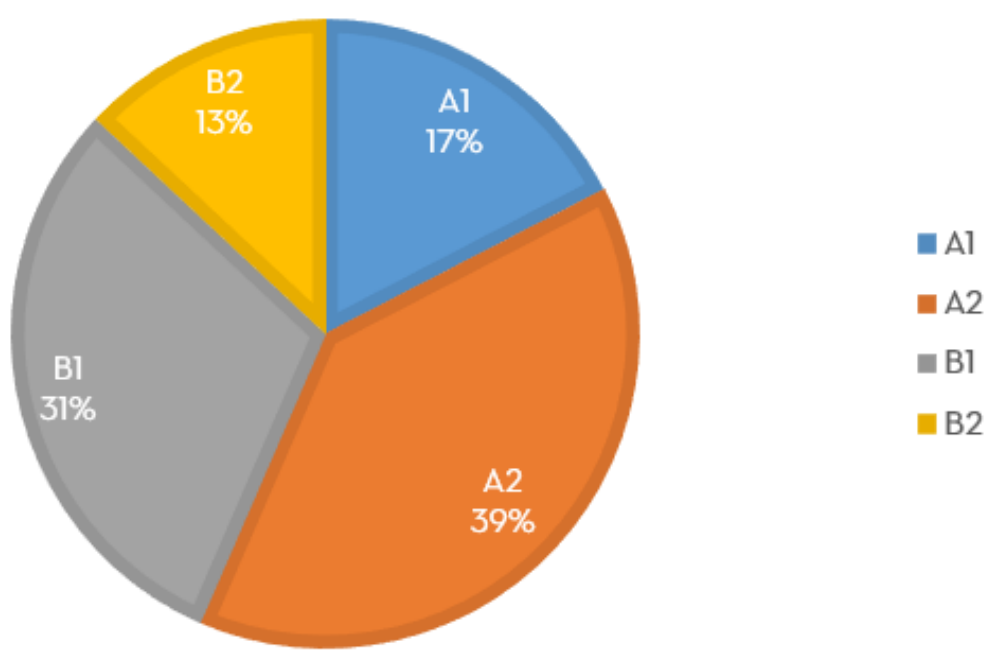

Gráfico 1 - Porcentagem em relação a quantidade de artigos utilizados e estrato de WebQualis Fonte: Elaboração própria com base nos dados bibliográficos. Salvador, 2014

A respeito da avaliação pelo portal WebQualis, $56,54 \%$ dos artigos utilizados para a pesquisa, é concebida a avaliação $A$, que atende a todos os critérios estabelecidos para o padrão de qualidade excelente, e que garante confiabilidade nos resultados utilizados, conforme o gráfico 1 acima.

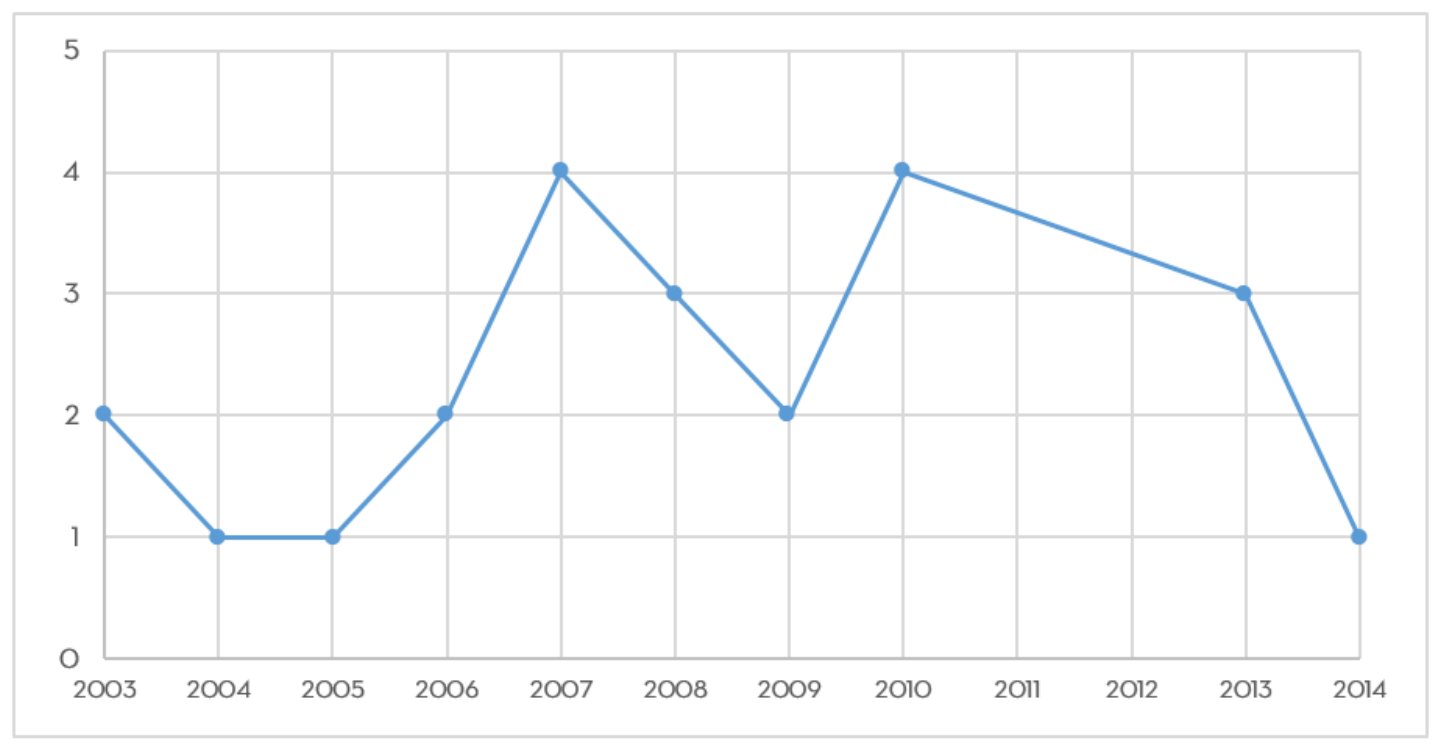

Gráfico 2 - Relação do ano de publicação e quantidade de artigos pesquisados

Fonte: Elaboração própria com base nos dados bibliográficos. Salvador, 2014 
Em relação ao ano de publicação dos 23 artigos citados, $26,1 \%$ foram no período de 2003 a 2006 ; $52,2 \%$ dos artigos no período de 2007 a 2010 e
$21,7 \%$ entre os anos de 2011 a 2014. O período mais representativo é o de 2007 a 2010 . A discussão sobre o autocuidado é um tema bastante atual e representativo nas pesquisas.

\begin{tabular}{|c|c|c|c|c|}
\hline AUTORES & TIPO DE ESTUDO & ANO & $\begin{array}{l}\text { REGIÃO DE } \\
\text { PRODUÇÃO }\end{array}$ & $\begin{array}{l}\text { REGIÃO DE } \\
\text { PUBLICAÇÃ̃O }\end{array}$ \\
\hline Baggio, MA; Formaggio, FM & Pesq de Campo & 2007 & Sul & Sul \\
\hline Baggio, MA; Erdmann, AL. & Pesq de Campo & 2010 & Sul & Sul \\
\hline Volcan, SMA; et al & Pesq de Campo & 2003 & Sul & Sudeste \\
\hline $\begin{array}{l}\text { Bellato, R; Araújo, PA; Ferreira FH; } \\
\text { Rodrigues FP; }\end{array}$ & Pesq de Campo & 2007 & Centro-Oeste & Sudeste \\
\hline Baggio, MA; Monticelli, M; Erdmann, AL. & Pesq de Campo & 2009 & Sul & Centro-Oeste \\
\hline Paschoalini, B; et al. & Pesq de Campo & 2008 & Sudeste & Sudeste \\
\hline $\begin{array}{l}\text { Fernandes, CJ; Portela, FL; Rotenberg, } \\
\text { L; Griep, HR. }\end{array}$ & Pesq de Campo & 2013 & Sudeste & Sudeste \\
\hline Celich, KLS, Restelatto, $M$ & Pesq de Campo & 2008 & Sul & Nordeste \\
\hline Espinha, DCM; Camargo SM; Silva SPZ; & Pesq de Campo & 2013 & Sudeste & Sul \\
\hline $\begin{array}{l}\text { Carmargo, TB; Lacerda, MR; Sarquis, } \\
\text { LMM }\end{array}$ & Pesq de Campo & 2010 & Sul & Sul \\
\hline Costa, FM; et al. & Pesq de Campo & 2014 & Centro-Oeste & Sudeste \\
\hline Oliniski, SR; Lacerda MR. & Pesq de Campo & 2006 & Sul & Sul \\
\hline Azambuja, EP; etal & Pesq de Campo & 2007 & Sul & Sudeste \\
\hline Schimidtz, DRC; Dantas, RAS & Pesq de Campo & 2006 & Sul & Sudeste \\
\hline Santos, VEP; Radunz, V. & Estudo de Caso & 2010 & Sul & Sudeste \\
\hline $\begin{array}{l}\text { Mendes, KDS; Silveira, RCCP; } \\
\text { Galvão, CM. }\end{array}$ & Rev Bibliográfica & 2008 & Sudeste & Sudeste \\
\hline Lunardi VL; et al. & Rev Bibliográfica & 2004 & Sudeste & Sudeste \\
\hline Manetti, ML; Marziale, MHP. & Rev Bibliográfica & 2007 & Sudeste & Nordeste \\
\hline Vitor, AF; Lopes, MVO; Araujo TL. & Rev Bibliográfica & 2010 & Nordeste & Nordeste \\
\hline Marqueze CE; Moreno CRC. & Rev Bibliográfica & 2005 & Sul & Sudeste \\
\hline Silva et al. & Rev Bibliográfica & 2009 & Norte & Sudeste \\
\hline Diógenes MAR; Pagliuca LMF. & Rev Bibliográfica & 2003 & Sul & Nordeste \\
\hline Zamberlan, $\mathrm{C}$ et al & Rev Bibliográfica & 2013 & Sul & Sul \\
\hline
\end{tabular}

Quadro 2 - Distribuição dos artigos quanto ao autor, tipo de estudo, ano, região de elaboração do estudo e região de publicação

Fonte: Elaboração própria com base nos dados bibliográficos. Salvador, 2014.

Quanto ao tipo de estudo, identifica-se a partir do Quadro 2, que os artigos selecionados foram diferenciados, sendo mais representativo a pesquisa de campo, estratégia utilizada pelas autoras, para ter uma percepção real dos profissionais quanto ao assunto discutido. Os artigos de revisão bibliográfica foram utilizados para dar embasamento teórico e conceitos. 
Os dados obtidos pelo portal Capes, com a última atualização em 17 de novembro de 2014, referente às instituições de ensino superior e especializações, têm a maior concentração no Sudeste do país (2.769), subsequente o Sul (1.186), Nordeste (1.035), Centro-Oeste (438) e a região do com a menor quantidade de cursos de pós-graduação é o Norte $(261){ }^{(6)}$

Nos artigos encontrados $56,5 \%$ foi elaborado na região Sul, e as publicações em periódicos na região Sul-Sudeste do país, resultou em $78,3 \%$ do total de artigos selecionados, podendo-se inferir a maior quantidade de instituições de ensino superior, resultado da concentração de pesquisadores, recursos humanos e investimentos financeiros.

O Nordeste precisa investir na elaboração de produção científica, dentre os 23 artigos utilizados, somente 04 foram publicados nessa região do país. Na região Sul e Sudeste são 18 publicações, 12 são de pesquisas de campo. A rotina dos enfermeiros e a percepção sobre o autocuidado são bastante semelhantes em todas as regiões que os trabalhos foram produzidos, e o descuidado é descrito em todas as pesquisas que tratam do assunto.

\section{TEORIA GERAL DA ENFERMAGEM POR OREM}

A enfermeira doutora Dorothea Orem, naturalizada americana, começou a escrever a Teoria Geral de Enfermagem na década de 50 e publicou o desfecho final em 1991. Durante anos esse assunto é discutido no mundo, como uma estratégia de qualidade de vida e autonomia que o ser humano precisa desenvolver, para estar bem com o psicológico, biológico, social e espiritual.(1)

A Teoria Geral da Enfermagem é composta por três teorias inter-relacionadas: Sistema de Enfermagem, Déficit de Autocuidado e Autocuidado, baseado na premissa de que os indivíduos podem cuidar de si próprios. ${ }^{(7)}$

A Teoria de Sistemas de Enfermagem é composta por quatro conceitos principais sendo estes, o ser humano como um ser pensante que tem a capacidade de refletir sobre si mesmo e o ambiente que o cerca; a relação com os profissionais da enfermagem, como provedora da prevenção, promoção e manutenção da saúde, o tratamento de doenças; a sociedade, tendo em vista que as pessoas adultas sejam responsáveis por si e pelo bem estar de seus dependentes. (1) Contudo quando o indivíduo está aparentemente bem e saudável, não se dá a devida importância e nem adota métodos preventivos sobre o autocuidado. Só sente a necessidade de valorizar os direitos de viver e rever o estilo de vida que tem, quando é acometido por uma doença ou lesão, que afeta o seu funcionamento integral. ${ }^{(2)}$

A Teoria do Déficit do Autocuidado é apresentada de fato na segunda edição do modelo de Orem, oferece subsídios ao cuidado, por estar essencialmente apoiada no princípio de que todos possuem potenciais, em diferentes graus, para cuidar de si mesmo e dos outros, sendo as ações recomendadas esboçadas na identificação do que pode ser realizado por si, e atividades que necessitarão da intervenção do outro; iniciar e manter relacionamentos entre o convívio social com a família e grupos; prescrever, prover e regular ajuda direta na rotina de vida diária, nas necessidades social, educacional e de cuidado. (7)

O Autocuidado surge como a promoção das atividades promovidas pelo cuidado pessoal demandado cotidianamente para regular o próprio funcionamento e desenvolvimento. $\mathrm{E}$ o déficit de autocuidado se relaciona ao comprometimento para realização do autocuidado. ${ }^{(7)}$

O ser humano compreendido como bio-psico-sócio-espitirual, que precisa se adaptar ao meio ambiente para atingir seus objetivos e para tanto precisa se autocuidar. É necessário manter o equilíbrio entre o bom funcionamento do corpo e a ausência de doença, através da promoção de saúde. Partindo desse ideal, adotamos um comportamento ético pela vida e a preocupação com o viver bem e com qualidade. ${ }^{(2)}$ 


\section{AS DIMENSÕES DO PROFISSIONAL ENFERMEIRO}

Os requisitos universais do cuidado holístico que englobam as esferas mental, emocional, espiritual e energética, ${ }^{(8)}$ ampliando a percepção para a alimentação, eliminação, atividade e descanso, solidão e interação social, prevenção e promoção da atividade humana. São fatores que quando comprometidos afetam a saúde e o desenvolvimento. ${ }^{(2)}$

$O$ autocuidado se tornou o tema mais abordado pela enfermagem brasileira nas últimas décadas, quando nota-se que a prevenção e promoção da saúde são medidas mais plausíveis, visando o bem estar e evitar a doença. ${ }^{(8)}$

Para compreender as dimensões do ser humano, é necessário um equilíbrio entre os fatores extrínsecos àqueles que são relacionados à moradia e ao ambiente trabalho, e os fatores intrínsecos que é a saúde física e mental do indivíduo. ${ }^{(7)}$

Adotar hábitos por uma vida saudável, realização profissional e um ambiente de trabalho que proporcione qualidade de vida, bom convívio com a chefia, boa relação com os colegas de trabalho, valorização profissional, remuneração justa e jornada de trabalho digna. São elementos essenciais para suprir a dimensão do profissional. ${ }^{(7)}$

\section{AUTOCUIDADO BIOLÓGICO}

Entre categorias envolvidas na formação do indivíduo, a que se apresenta com maior desequilíbrio entre o déficit e o autocuidado, é o fator biológico, partindo do princípio que a enfermagem não tem carga horária predefinida.

As responsabilidades profissionais que comprometem o sono/repouso são percebidos como fatores estressores, profissionais da saúde precisam do corpo descansado para garantir o bom desempenho de suas atividades. (3)

Profissionais que atuam na área da saúde têm que ser cautelosos e promover o autocuidado fazendo uso dos equipamentos de proteção individual, inclusive por ser exposto a risco de contaminação por material biológico; ter a consciência da precaução frente a qualquer circunstância e a todos os pacientes, é ter ciência de seguir a técnica correta, ter um processo de trabalho organizado, concentrar-se na realização das atividades e prestar seu serviço em um ambiente que proponha condições harmônicas e ergonômicas adequadas para exercer seu trabalho.(9)

A forma como o processo de globalização no Brasil e no mundo atual tem reestruturado o modo de vida, principalmente na alimentação, com consumo excessivo de enlatados, lanchonetes que visam a produção de comidas rápidas, e consequentemente tem como ingrediente principal os conservantes, gorduras e frituras. Definindo outros padrões de saúde-doença, a obesidade, hipertensão e diabetes, principais fatores causais, ${ }^{10)}$ Devido o tempo exíguo as enfermeiras relatam um consumo de moderado a excessivo de alimentos; consumo de moderado a alto de café; ausência de práticas de atividade física. ${ }^{(11)}$

Os profissionais de saúde, muitas vezes, esquecem o autocuidado, pois na visão da sociedade, o ser educador-cuidador não adoece e não se cansa. Portanto frequentar médicos para que seja tratado o diagnóstico e não fazer prática da automedicação para tratar medidas paliativas, são entendimentos apenas de teoria e orientação aos pacientes, tendo em vista que a enfermagem por possuir fácil acesso a drogas é um risco que o profissional se expõe para intoxicação, reação alérgica e potencializar o problema, ao invés de sanar tende a mascarar a doença. (3)

O autocuidado possibilita a prevenção e a promoção com a saúde, e, quando este se mostra prejudicado, é comum encontrar profissionais com episódios depressivos, hipertensos, problemas músculo esqueléticos, distúrbios de sono, entre outras patologias decorrentes do descuidado.(11)

\section{AUTOCUIDADO PSICOLOGICO}

O ambiente laboral é comumente um espaço desencadeador de situações de estresse, fadiga física e mental, tendo as condições culturais e sociais 
de cada ser, influenciando no processo de cuidado dos seres. ${ }^{(12)}$

A complexidade do trabalho da enfermagem exige concentração, estado de alerta, rapidez e qualidade de execução da técnica. Sendo assim, uma longa jornada de trabalho pode prejudicar não apenas a saúde dos profissionais, como também o cuidado do paciente. ${ }^{(11)}$

O profissional que tem a realização de seus valores por meio dessa atividade somatizado a um ambiente de trabalho que promova qualidade de vida, consequentemente haverá satisfação no trabalho, o que permite maiores resultados para a organização e para a vida do empregado. ${ }^{(13)}$

A Qualidade de Vida no Trabalho (QVT) como linha de pesquisa da ciência comportamental, é uma expressão abrangente e dotada de subjetividade. O conceito de QVT é dotado por noções de motivação, satisfação, saúde e segurança no trabaIho. ${ }^{(14)}$ Perpassa pelas condições de trabalho (pagamento, promoção e reconhecimento), agentes do trabalho (colegas e subordinados, supervisores, empresa/organização), analisando os fatores causais em suas inter-relações. ${ }^{(13)}$

A satisfação no trabalho é considerada um indicador de qualidade de vida no trabalho, ${ }^{(14)}$ o que afeta os aspectos comportamentais e a saúde física e mental do trabalhador, ${ }^{(13)}$ promovendo o autocuidado e consequentemente reduz acidente com material biológico, erros profissionais, estresse e insatisfação. ${ }^{(9)}$

\section{AUTOCUIDADO SOCIAL}

Os seres humanos precisam um do outro para a sua autonomia, sobrevivência, cuidado pessoal e profissional. Para a existência do coletivo, são necessárias a inter-relação e a interdependência, tendo em vista a individualidade por meio da cultura, educação e linguagem..$^{(12)}$

O grande prazer da vida reside na relação com a família e com os amigos. Compartilhar experiências é uma relação saudável consigo mesmo e com os outros, imprime generosidade às relações humanas, que também repercute no autocuidado. ${ }^{(3)}$

No trabalho de enfermagem salienta que há situações conflituosas vivenciadas, aliadas à pressão do cotidiano, assim como às condições de trabaIho e às relações interpessoais, fatores que comprometem o cuidado prestado ao outro e a si mesmo no processo de viver saudável, desencadeando a doença, desestruturação mental e a loucura.(3)

Os profissionais enfermeiros convivem mais tempo no ambiente de trabalho que em seu domicilio, e partilham sentimentos, experiências, conquistas semelhantes durante a rotina, é essencial à instituição empregadora intermediar esse ambiente para promover uma relação amigável entre os profissionais para um bom convívio diário. Considerando essa relação relevante para um cuidado com qualidade, contínuo e eficaz para o paciente, ao labor mais harmônico no intuito de reduzir situações de estresse. ${ }^{(12)}$

A classe de enfermagem partilha de sentimentos, experiências e conquistas semelhantes durante a rotina, laços de amizade entre os colegas são formados e ultrapassam o espaço institucional. Trabalhar com respeito e com colegas amigos, torna o ambiente mais prazeroso e com satisfação profissional. ${ }^{(13)}$

Autocuidado é considerado uma prática reflexiva das ações dos sujeitos que acontecem na relação com o outro. Para a prática do autocuidado ser efetiva e eficaz, faz-se necessário o ser cuidado pela família, os colegas de trabalho, a instituição empregadora e também o cuidar do outro não restringindo somente aos pacientes, mas aos familiares e amigos. ${ }^{\left({ }^{9}\right)}$

O cuidado não é considerado apenas no sentido de tratar, é além da integridade física, é um sentido mais amplo como um cuidado emocional, por meio do relacionamento com o outro, expressão de interesse e carinho. ${ }^{(3)}$

\section{AUTOCUIDADO ESPIRITUAL}

Wanda de Aguiar Horta, brasileira, doutora em enfermagem pela Universidade de São Paulo, defendeu e 
publicou a Teoria sobre as "Necessidades Humanas Básicas", colocando a espiritualidade como uma necessidade que precisa ser cuidada e observada pelo enfermeiro no planejamento da assistência, contudo é preciso revisar como anda o desenvolvimento espiritual desses profissionais. ${ }^{(15)}$

A questão da religiosidade é muito ampla, e sua mensuração é bastante complexa. Para familiarizar-se com as crenças do próximo, é necessário obter uma história espiritual, entender o papel da religião para identificar as necessidades espirituais nos momentos de dificuldade. ${ }^{(16)}$

$\mathrm{Na}$ formação de enfermagem é abordada a temática do processo de morte, de maneira muito rápida e superficial. Essa situação gera um despreparo e tende a limitar na maioria das vezes no cuidado com o paciente, pela angústia, medo e tristeza, considerando como fracasso terapêutico, não compreendendo que o processo de morte é parte integrante da vida. ${ }^{(17)}$

É esperado que os enfermeiros, por lidar cotidianamente com a morte do outro, compreendesse melhor o processo e seu significado, contudo por ser o profissional que tem maior contato e relação com o paciente e seus familiares em alguns momentos, é não raro, mais difícil para a enfermagem a influencia nos sentimentos da pessoa/profissional, no processo de morte. ${ }^{(17)}$

Para a psicologia, a religiosidade está presente quando se tem esperança sendo chamada de "energia transformadora", em que lhe traz estímulo e coragem para encarar a vida, existindo espaço tanto para a ciência como para os aspectos psicoespitiruais, inclusive a fé religiosa é o melhor recurso para enfrentar a situação de adoecimento. ${ }^{(16)}$

O cuidado a essas pessoas exige que o cuidador se reconheça também como um ser cuja finitude Ihe é inerente, e que a crença em uma religião auxilia ao processo de morte da maneira tranquila, digna e sem ansiedade. Acredita-se que certa maturidade só vem com a experiência. ${ }^{(17)}$

A enfermagem necessita de um preparo adequado na perspectiva de amadurecer os sentimentos, dentro de um processo de autocompreensão e de aceitação de que todas as pessoas um dia findam sua vida física. ${ }^{(17)}$

\section{AS ATRIBUIÇÕES DO DESCUIDADO}

A categoria de enfermagem não tem carga horária e piso salarial predefinido, havendo a necessidade de conciliar mais de um emprego para manter o padrão de vida. Essa situação leva esses profissionais a permanecerem no ambiente dos serviços de saúde a maior parte do tempo de sua vida produtiva, consequentemente o aumento da exposição aos riscos existentes nesses locais e prejuízo para sua Qualidade de Vida no Trabalho. ${ }^{(14)}$

Para avaliar a qualidade de vida geral, o entretenimento é um dos principais aspectos para a saúde física e mental dos trabalhadores, e os estudos estão comprovando que a enfermagem apresenta diminuição do tempo para as atividades de lazer. ${ }^{(14)}$

A enfermagem, por possuir mais de um vínculo profissional, ainda está exposta às jornadas extremamente longas e desgastantes. Sendo importante notar o predomínio do sexo feminino, cabendo às mulheres ainda o trabalho doméstico. ${ }^{(11)}$

Com às inúmeras atividades que são atribuídas, o profissional carece de tempo para pensar no seu autocuidado, e entra na rotina que é proposta pelos serviços. Enquanto cuidam do outro, sentem-se realizados, mas não oferecem a si o cuidado devido. ${ }^{(12)}$

Os fatores que contribuem significativamente para o descuidado estão relacionados a ergonomia do ambiente laboral, pelas condições de poder inquestionável de superiores, serviço mal remunerado, jornada dupla, concomitante a não contemplação de suas necessidades básicas bio-psico-socio-espiritual. ${ }^{(3)}$

Caso alguma necessidade humana básica esteja prejudicada, seja ela a falta de boa alimentação, dormir o tempo necessário e até mesmo o retorno financeiro, vai intervir na eficácia do cuidado total prestado ao outro. ${ }^{(3)}$

Os profissionais alegaram que esse prejuízo na qualidade de vida: ausência de prática de exercício 
físico, sono de curta duração, alto consumo de frituras, está relacionado as atribuições da profissão. ${ }^{(11)}$

A desvalorização do trabalho dificulta a obtenção de condição para melhor desenvolver o autocuidado e a realização humana, contribuindo para uma baixa autoestima. ${ }^{(8)}$

Com todos esses fatores, os profissionais estão suscetíveis a erros técnicos que podem causar danos à saúde do paciente, a perda do exercício profissional, a julgamentos do Código Civil Brasileiro e o Código de Ética do Profissional de Enfermagem. ${ }^{(18)}$

Destaca-se na Seção I, das relações com a pessoa, família e coletividade, quanto à responsabilidade e deveres, no art. 12: "Assegurar à pessoa, família e coletividade assistência de enfermagem livre de danos decorrentes de imperícia, negligência ou imprudência." No art. 13: "Avaliar criteriosamente sua competência técnica, científica, ética e legal e somente aceitar encargos ou atribuições, quando capaz de desempenho seguro para si e para outrem." Sendo assim, fica a critério do profissional que esteja com o sono e repouso comprometido, por exemplo, julgar-se capaz ou não, de prestar assistência.

\section{CONSIDERAÇÕES FINAIS}

O tema em questão tem sido discutido no processo de formação, contudo na percepção da enfermagem orientar sobre o autocuidado do paciente, e poucas vezes é refletido a promoção do cuidado consigo, que deveria ser reforçado para os profissionais que estão entrando no mercado de trabalho, para não recorrer ao mesmo equívoco. Mediante os artigos coletados, pode-se concluir que este cuidado deve ser bidirecional entre enfermeiro-paciente, atingindo assim as dimensões: biológica, psicológica, social e espiritual de ambos.

$\mathrm{Na}$ classe de enfermagem é comum à dupla jornada de trabalho em busca de melhores condições financeiras, e muitas mulheres, ainda, estendem a terceira jornada aos afazeres domésticos. O tempo exíguo para praticar o autocuidado, a dimensão biológica quando prejudicada desenvolve uma sequência de doenças cardíacas, musculares, a falta de ar, tontura, distúrbio do sono, oscilação de humor, aumento de estresse, podendo desencadear, como consequência, uma perda de motivação em relação ao trabalho e a depressão. Essa forma de reação (sobrecarga emocional) é vivenciada de diferentes formas, portanto esse quadro não deve ser generalizado a todos os profissionais.

Compreendendo o ser humano como o único e que traz consigo uma história de vida, visão de mundo, bagagem de cultura, valores e crenças diferenciados, e partindo do princípio de que as pessoas têm a necessidade do cuidado interativo consigo mesmo e com o outro, não se pode ignorar a influencia que o contexto familiar e social exerce sobre o autocuidado e a saúde.

O cuidado transcende, do meio físico para o espiritual, e se a enfermeira der a devida importância a esta dimensão, possibilita-Ihe desenvolver estratégias para promover esse cuidado ao paciente e a si própria, bem como o enfretamento da morte, a (principal) circunstância impactante enfrentada pela categoria.

As estruturas das instituições poucas vezes valorizam a ergonomia, para favorecer as condições de trabalho, um local que ofereça o mínimo de conforto no ambiente de descanso, espaço harmônico para compartilhar experiências e trocar informações e toda estrutura de mobília que seja adaptável para qualquer indivíduo.

É altamente relevante que os gestores de saúde adotar estratégias e medidas coletivas que priorizem um ambiente laboral produtivo, investir na saúde do empregado em todas as suas dimensões, pois o déficit de autocuidado profissional o torna mais suscetível a falhas na prestação de cuidado ao outro e até erros irreversíveis. Sendo assim, a tomada de consciência sobre o autocuidado e a criação de um ambiente ocupacional promotor e provedor de saúde irá produzir mais segurança e satisfação aos trabalhadores, clientes e, consequentemente, retorno financeiro à instituição. 
Em síntese com a discussão apresentada fica evidente que o cuidado é a essência do ser humano. As instituições formadoras não trazem o tema do autocuidado no bojo dos seus componentes curriculares. Se a enfermagem eminentemente se forma para cuidar, existe uma carência na formação do enfermeiro sobre o autocuidado no exercício profissional, para que venha ser um cuidador diferenciado.

Pesquisas sobre o tema são necessárias, visando instruir a profissional enfermeira sobre o autocuidado e incentivar as instituições a adotar gestão do cuidado aos colaboradores. Estudos que abordem a importância do autocuidado dos profissionais de enfermagem devem ser estimulados, aprofundados e difundidos para servir de subsídio às legislações que fundamentam a saúde destes trabalhadores.

\section{REFERENNCIAS}

1. Diógenes MAR, Pagliuca LMF. Teoria do Autocuidado: análise critica da utilidade na prática da enfermeira. Rev Gaúch Enferm. 2003 [acesso em: 2014 ago 13]; 24(3):28693. Disponível em: http://www.seer.ufrgs. br/RevistaGauchadeEnfermagem/article/ download/4458/2399

2. Silva IJ et al.Cuidado, autocuidado e cuidado de si: uma compreensão paradigmática para o cuidado de enfermagem. Rev Esc Enferm USP. 2009 [acesso em: 2014 jul 16]; 43(3):697703. Disponível em: http://dx.doi.org/10.1590/ SO080-62342009000300028

3. Baggio MA, Formaggio FM. Profissional de enfermagem: compreendendo o autocuidado. Rev Gaúch Enferm. 2007 [acesso em: 2014 jul 14];28(2):236-241. Disponível em: http://seer.ufrgs. br/index.php/RevistaGauchadeEnfermagem/ article/view/3168/1739

4. Baggio MA, Monticelli M, Erdmann AL. Cuidando de si, do outro e "do nós" na perspectiva da complexidade. Rev Bras Enferm. 2009 [acesso em: 2014 jul 12];62(4):627-31. Disponível em: http://www.scielo.br/pdf/reben/ v62n4/23.pdf
5. Mendes KDS, Silveira RCCP, Galvão CM. Revisão integrativa: método de pesquisa para a incorporação de evidências na saúde e na enfermagem. Texto \& Contexto Enferm. 2008 [acesso em: 2014 set 24]:17(4). Disponível em: http://www.scielo.br/scielo.php?script=sci_arttext \&pid=S0104-07072008000400018

6. Coordenação de Aperfeiçoamento de Pessoal do Nível Superior [Internet]. Brasília, DF; nov. 2014 [acesso em 2014 jul 12]. Disponível em: http://conteudoweb.capes.gov.br/conteudoweb/ ProjetoRelacaoCursosServlet?acao=pesquisar Regiao

7. Vitor AF, Lopes MVO, Araujo TL. Teoria do déficit de autocuidado: análise da sua importância e aplicabilidade na prática de enfermagem. Esc Anna Nery Rev Enferm. 2010 [acesso em: 2014 jul 14];14(3):611-616. Disponível em: http://www.scielo.br/pdf/ean/v14n3/ v14n3a25.pdf

8. Celich KLS, Restelatto M. Ambiente hospitalar: espaço para a construção e crescimento do ser humano. Rev Enferm. UFPE on line. 2008 [acesso em 2014 jul 14];2(4):348-56. Disponível em: http://www.revista.ufpe.br/ revistaenfermagem/index.php/revista/article/ viewArticle/319.

9. Carmargo TB, Lacerda MR, Sarquis LMM. Cuidado de si e acidente com material biológico: teoria Fundamentada nos dados. Brazilian Journal Nurse. 2010 [acesso em: 2014 jul 12]; 9(1). Disponível em: http://www. objnursing.uff.br/index.php/nursing/article/ view/j.1676-4285.2010.2797/617

10. Azambuja EP, Kerber NPC, Kirfchhof AL.A saúde do trabalhador na concepção de acadêmicos de enfermagem. Rev. Esc Enferm USP. 2007 [acesso em: 2014 nov O2]:41(3):355362. Disponível em: http://dx.doi.org/10.1590/ S0080-62342007000300003.

11. Fernandes CJ, Portela FL, Rotenberg L, Griep HR. Jornada de trabalho e comportamentos de saúde entre enfermeiros de hospitais públicos. Rev Lat Am Enferm. 2013 Set-out [acesso em: 2014 jul 14]; 21(5). Disponível em: http:// www.scielo.br/pdf/rlae/v2ln5/pt_0104-1169rlae-21-05-1104.pdf.

12. Baggio MA, Erdmann AL. Relações múltiplas do cuidado de enfermagem: o emergir do cuidado 
"do nos". Rev Lat Am Enferm. 2010 [acesso em 2014 jul 12];18(5):895-9O2. Disponível em: http://dx.doi.org/10.1590/SO10411692010000500009 .

13. Marqueze CE, Moreno CRC. Satisfação no trabalho - uma breve revisão. Rev Bras Saúde Ocup. 2005 [acesso em: 2014 set 25];30(112):69-75. Disponível em: http://www. scielo.br/pdf/rbso/v30n112/O7.pdf

14. Schmidt DRC, Dantas RAS. Qualidade de vida no trabalho de profissionais de enfermagem, atuantes em unidades do bloco cirúrgico, sob a ótica da satisfação. Rev Lat Am Enferm. 2006 [acesso O2 nov 2014];14(1):54-60 Disponível em: http://www.scielo.br/pdf/rlae/v14nl/ v14nlaO8.pdf

15. Volcan SMA et al. Relação entre bem-estar espiritual e transtornos psiquiátricos menores: estudo transversal. Rev Saúde Pública. 2003 [acesso em: 2014 jul 24 ];37(4). Disponível em http://www.scielosp.org/pdf/rsp/v37n4/16778. pdf
16. Espinha DCM, Camargo SM, Silva SPZ, Pavelqueires S, Lucchetti G. Opinião dos estudantes de enfermagem sobre saúde, espiritualidade e religiosidade. Rev Gaúch Enferm. 2013 [acesso em: 2014 ago 19];34(4):98-106. Disponível em: http://www. scielo.br/pdf/rgenf/v34n4/13.pdf

17. Bellato R, Araújo PA, Ferreira FH, Rodrigues FP. A abordagem do processo do morrer e da morte feita por docente em um curso de graduação em enfermagem. Rev Acta Paul Enferm 2007 [acesso em: 2014 ago 19]; 2O(3):255-63. Disponível em: http://www.scielo. br/pdf/ape/v2On3/aO3v2On3.pdf

18. Conselho Federal de Enfermagem (BR). Legislação básica para o exercício da enfermagem. Resolução COFEN nº 311/2007. Aprovação a Reformulação do Código de Ética dos Profissionais de Enfermagem. Brasília, DF; 2013. Seção 1, p-105. 